\title{
Editorial
}

\section{Decoding the Pot Belly}

"The Way to a Man's Heart is Through His Stomach" - Fanny Fern (1811-1872)

Cardiovascular Disease (CVD) has emerged as the largest cause of morbidity and mortality in the present times. Central Obesity, the Pot Belly, is an undeniable risk factor for CVD, specially in the Indian subcontinent. ${ }^{1}$ In contrast to abdominal obesity it is the amount of visceral fat that contributes to this increased risk through dyslipidemia and pro inflammatory conditions largely contributed to by Insulin resistance. Increased visceral fat also tends to cluster with other risk factors such as hypertension, impaired glucose tolerance, a condition that has been designated as the Metabolic syndrome (MS).

An important component of MS is the waist circumference (WC). But WC is only a surrogate marker of increased visceral fat which is more accurately determined by Tomography (CT). While CT may help identify at risk individuals not detected by conventional criteria it is not cost effective and radiation issues make it unsuitable for screening large groups.

Bioelectrical Impedance Analysis (BIA) based on detection of resistance between visceral fat and components of other organs is a non-invasive, inexpensive, portable, method of measuring visceral fat that does not require operator skill, or much patient cooperation.

Miva Rayo et $\mathrm{al}^{2}$ found that Visceral Fat Area (VFA) determined By BIA correlates well with CT $(r=0.88 ; p \leq 0.0001)$ which is better than the correlation of WC with CT $(r=0.73-0.76)$. Shoji $\mathrm{K}$ et $\mathrm{al}^{3}$ have reported that while WC correlates most with raised triglycerides, Visceral Fat in addition correlates also with blood pressure, HDL and other lipid abnormalities and may help detect at risk patients with dyslipedemia, not identified by WC.

In this issue of the journal Puri et $\mathrm{al}^{4}$ have determined Visceral Fat Rating (VFR) using BIA in patients with Coronary Artery Disease (CAD) on intensive station therapy comparing them with healthy controls. They have found a VFR of $>12$ to be associated with increased WC, increased Triglycerides, Total and low density Cholesterol and lower High Density Cholesterol as compared to those with VFR $<12$ and healthy controls, there being no difference between the latter two.
These findings confirm that high visceral fat as determined by BIA identifies atherogenic dyslipidemia and its associated CVD risk.

They have also inferred that statins may not as effective in those with high versus those with low visceral fat. Do those with low visceral fat respond better to statins and those with high rates, resistant? It is likely that the association between lower visceral fat and better lipid profiles has the common factor of a more intensive life style modification. It may however be suggested that non responders to statin therapy be evaluated for visceral fat using a simple technique do BIA and those above a mean value of $>12$ be subjected to focused life style modification, intensification of statin or add on adjunctive therapy for risk reduction.

Before we advocate the routine use of visceral fat measurement as an independent risk factor for CVD and as a guide for statin therapy, larger surveys and studies would be needed and it would be worthwhile to look at visceral fat in patients with $\mathrm{CAD}$ who have no conventional risk factors; also to see the correlation between visceral fat and presentation, severity and natural course of the disease. BIA is an encouraging step towards assessment of visceral fat but it also has limitations of clinical and environmental factors that have to be considered and the methodology standardized, as also expressed by the authors of this report.

\section{R E F E R E N C E S}

1. Yusuf S, Hawken S, Ounpuu S, et al, INTERHEART Study Investigators. Effect of potentially modifiable risk factors associated with myocardial infarction in 52 countries (the INTERHEART study): case-control study. Lancet. 2004;364:937-952.

2. Ryo M, Maeda K, Onda T, et al. A new simple method of measurement of visceral fat accumulation by bioelectrical impedance. Diabetes Care. 2005 Feb;28:451-453.

3. Shoji K, Maeda K, Nakamura T, et al. Measurement of visceral fat by abdominal bioelectrical impedance analysis is beneficial in medical checkup. Obes Res Clin Pract. 2008 Dec;2:I-II.

4. Puri A, Singh V, Pandey S, Singh CK, Singh SRK. Visceral fat rating is a useful indicator in risk assessment among coronary 
artery disease patients treated with aggressive lipid lowering therapy. Clin Epidemiol Glob Health. 2014;2:127-132.

V.S. Narain*

Professor, Department of Cardiology, King George's Medical University, Lucknow, Uttar Pradesh, India

Gaurav Chaudhary

Senior Resident, Department of Cardiology, King George's Medical University, Lucknow, Uttar Pradesh, India
*Corresponding author.

E-mail address: vnarain@yahoo.com

10 October 2014

Available online 22 November 2014

http://dx.doi.org/10.1016/j.cegh.2014.10.003

2213-3984/Copyright @ 2 2014, INDIACLEN. Publishing Services by Reed Elsevier India Pvt Ltd. All rights reserved. 